\title{
Medical Thoracoscopic Thermal Ablation Therapy for Metastatic Pleural Tumors with Malignant Effusion: An Exploratory Retrospective Study
}

\author{
Zhonglun Mai $\mathbb{D}^{1, *}$ \\ Bin Feng ${ }^{2, *}$ \\ Qianwen $\mathrm{He}^{3}$ \\ Qixiao Feng' \\ 'Department of Thoracic Oncology, \\ Cancer Center, Integrated Hospital of \\ Traditional Chinese Medicine, Southern \\ Medical University, Guangzhou, \\ Guangdong Province, 510315, People's \\ Republic of China; ${ }^{2}$ Department of \\ Oncology, The First Affiliated Hospital of \\ Jinan University, Guangzhou, Guangdong \\ Province, 510630, People's Republic of \\ China; ${ }^{3}$ Department of Geriatrics, \\ Integrated Hospital of Traditional \\ Chinese Medicine, Southern Medical \\ University, Guangzhou, Guangdong \\ Province, 510315, People's Republic of \\ China
}

*These authors contributed equally to this work
Purpose: Malignant pleural effusion (MPE) is an intractable condition. The current mainstream therapies for MPE, ie, indwelling pleural catheter and pleurodesis, have some drawbacks. In this retrospective study, we explored the efficacy and safety of medical thoracoscopic thermal ablation (argon plasma coagulation, APC) therapy for metastatic pleural tumors with MPE.

Patients and Methods: A total of 176 patients were enrolled and divided into catheter pleural drainage (CPD) group $(n=77)$, non-ablation group $(n=46)$, and thermal ablation group $(n=53)$. Propensity score matching (PSM) was used for between-group comparisons to minimize bias. The primary endpoints were pleural effusion objective response rate (ORR) and time to progression (TTP); secondary endpoints included overall survival (OS), chest-tube duration, and safety.

Results: Thermal ablation group and non-ablation group showed significantly higher ORR and shorter chest-tube duration versus the CPD group (ORR: thermal ablation, $88.2 \%$ vs $66.7 \%, P=$ 0.004; non-ablation, $88.4 \%$ vs $64.4 \%, P=0.042$; chest-tube duration: thermal ablation, 4.90 vs 7.24 days, $P<0.001$; non-ablation, 5.73 vs 7.33 days, $P=0.010$ ). Thermal ablation group exhibited longer TTP than the CPD group (median, 13.7 vs 7.3 months, $P=0.001$ ) and the nonablation group (median, 13.6 vs 10.3 months, $P=0.037$ ). OS in the thermal ablation group was numerically longer than that in the CPD group with marginally significant difference $(P=0.055)$. There was no significant difference in the frequency of adverse events or changes in vital signs between thermal ablation and non-ablation groups.

Conclusion: Medical thoracoscopic thermal ablation (APC technique) therapy was effective and safe in the treatment of metastatic pleural tumors with MPE for improving ORR and TTP.

Keywords: medical thoracoscopy, thermal ablation, argon plasma coagulation, metastatic pleural tumor, malignant pleural effusion, non-small-cell lung cancer

\section{Introduction}

Pleura is one of the most common metastatic sites of lung cancer. Pleural metastasis typically appears as multiple masses of various sizes, nodular appearance, or plaques. ${ }^{1,2}$ The majority of these patients have malignant pleural effusion (MPE), which eventually produces symptoms such as dyspnea, reducing the quality of life and functional status. ${ }^{3}$ Lung cancer is classified as stage IV once MPE appears, indicating advanced, unresectable disease. The reported median survival of these patients is 3-12 months with 5-year survival rate of $<2 \%$.

Palliative care with minimal adverse events is the cornerstone of MPE management. ${ }^{6}$ Currently, the mainstream therapies include indwelling pleural catheter
Correspondence: Qixiao Feng

Tel $+86 I 8520088212$

Email cxhfqx@163.com

Zhonglun Mai

Email maizhonglun@I26.com 
(IPC) and talc pleurodesis. ${ }^{7,8}$ However, both methods have their own limitations: (1) It takes a long time (median 52 days) to achieve pleurodesis in patients who inserted IPC to drain a maximum of 1 liter of fluid on a daily basis. ${ }^{9}$ Moreover, repeated draining of the pleural effusion may cause excessive protein loss. Furthermore, catheter care is inconvenient especially when the patients are discharged home, and prolonged indwelling catheters may increase the risk of infection. (2) Some patients may develop severe complications after talc pleurodesis, such as chest pain $(68 \%)$, fever $(47 \%)$, and rarely, respiratory failure $(0.7-$ $9 \%$ ), and even adult respiratory distress syndrome with a fatality rate of $2.9 \% .^{10-12}$ In addition, there are other methods such as intrapleural hyperthermic perfusion chemotherapy and surgical procedures (pleuroperitoneal shunts or extrapleural pneumonectomy); however, there is a lack of adequate evidence base to support their use. ${ }^{13}$

Therefore, the development of new minimally invasive therapeutic modalities for management of effusion and metastatic pleural tumors is a key imperative. Medical thoracoscopy, which can be performed in an endoscopy suite with a single small incision under local anesthesia and conscious sedation, may be suitable for use in patients with advanced disease. ${ }^{14}$ However, it is mainly used for the diagnosis of pleural diseases and is rarely applied for the treatment of malignant pleural tumors. ${ }^{15}$ Thermal ablation, mainly including Argon Plasma Coagulation (APC), Laser Photoresection (LPR) and electrocautery, has been applied for the destruction of cancerous tissue with minimal damage to the surrounding tissue. These modalities have been widely used under digestive tract endoscopy. ${ }^{16}$ Recent years have witnessed rapid advances in the field of respiratory endoscopic thermal ablation, especially for the treatment of malignant central airway stenosis, but not pleural diseases. ${ }^{17} \mathrm{In}$ our clinical practice, we explored the use of thermal ablation therapy for metastatic pleural tumors under medical thoracoscopy and found it a particularly convenient method for management of effusion. This finding motivated us to conduct a retrospective study to investigate whether patients with metastatic pleural tumors really benefit from this therapy.

\section{Methods}

\section{Patients Selection}

Data pertaining to patients diagnosed with pleural metastatic tumors with MPE between May 2015 and June 2019 at the
Integrated Hospital of Traditional Chinese Medicine, Southern Medical University were retrospectively analyzed. This study was conducted in accordance with the World Medical Association Declaration of Helsinki and was approved by the Ethics Committee of the Integrated Hospital of Traditional Chinese Medicine, Southern Medical University (Grant No. NFZXYEC2019001). All patients provided written informed consent before any study-specific procedures. Two investigators independently extracted the data from the medical records management system according to the following criteria. Inclusion criteria: (1) The primary tumor: non-small cell lung cancer; (2) diagnosis of MPE based on imaging combined with pleural biopsy or fluid cytology; (3) symptomatic patients who underwent catheter pleural drainage or medical thoracoscopic therapy including non-ablation and thermal ablation; (4) Karnofsky performance scale (KPS) score $>60$; (5) patients received standard systemic chemotherapy. Exclusion criteria: (1) patients who received targeted therapy or immunotherapy; (2) MPE was previously treated; (3) computed tomography scan showing obvious lung trapping ( $<50 \%$ of lung surface in apposition to the chest wall); (4) extensive pleural adhesions detected on medical thoracoscopy; (5) electrocautery therapy; (6) LPR therapy; (7) patients with severe cardiopulmonary dysfunction.

Data extracted by the two investigators were crosschecked, and in case of any differences, a third investigator was consulted.

\section{Propensity Score Matching}

All eligible patients were categorized into three groups according to the therapy received: catheter pleural drainage (CPD) group, non-ablation group, and thermal ablation group. Patients were then matched (1:1 ratio) using propensity score matching (PSM; the caliper value: 0.02 ) based on age, sex, KPS score, primary tumor, tumor stage, and amount of MPE for pairwise comparisons: thermal ablation and CPD, non-ablation and thermal ablation, $\mathrm{CPD}$ and non-ablation.

\section{Treatment}

\section{Systemic Antitumor Therapy}

Each eligible patient received systemic standard chemotherapy in accordance with the National Comprehensive Cancer Network (NCCN) guidelines. Patients who received targeted therapy or immunotherapy were excluded due to their significant effect in improving overall survival (OS) and progression-free survival (PFS) in patients with non-small-cell lung cancer, which may have biased the results of our study. 

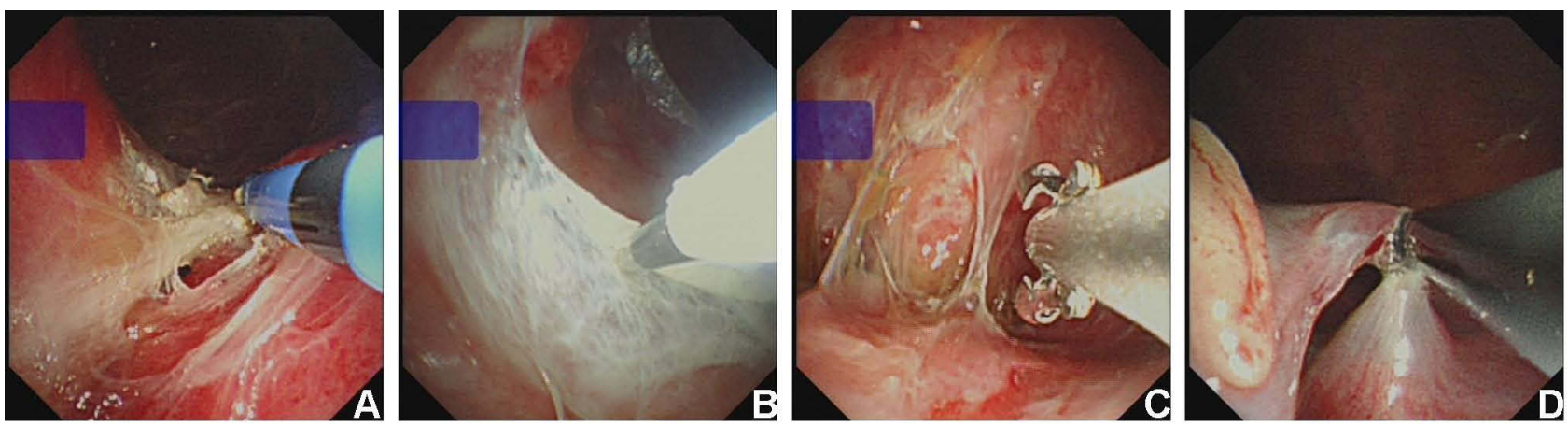

Figure I Removal of adhesions resembling spider webs by different approaches. (A) APC; (B) cryoprobe; (C) biopsy forceps; (D) electrocautery.

\section{Intrapleural Treatment Choice}

No specific protocol was used to choose a certain method for these patients; the choice of treatment mainly depended on their willingness. In the earlier phase of the study reference period, the majority of patients received CPD. In the later phase, we tended to encourage patients to receive medical thoracoscopy thermal ablation, especially those with large amount of MPE or multiple pleural nodules on imaging. In some cases, where the pathological diagnosis of the primary tumor was difficult, we employed medical thoracoscopy to clarify the diagnosis and placed the chest tube without thermal ablation.

\section{Medical Thoracoscopy}

Preoperative preparation: Lung and heart function of the patients were evaluated by blood gas analysis and ECG, and if possible, by pulmonary function tests. Routine laboratory investigations, such as coagulation parameters, serum electrolytes, serum creatinine, glucose, liver and renal function indices and complete blood count were performed. Intravenous midazolam $(0.05 \mathrm{mg} / \mathrm{kg})$ and dezocine $(0.1 \mathrm{mg} / \mathrm{kg})$ were administered for sedation and analgesia, respectively. Operation: The patient was placed in a lateral decubitus position with the involved side up. A point of entry with a $1.5-2 \mathrm{~cm}$ incision was selected, usually parallel to and in the middle of the fourth or fifth intercostal space at the midaxillary line, which was localized by $\mathrm{CT}$ image to avoid insertion of the trocar in the area of adhesions. Then, the semi-flexible thoracoscope (LTF-240, Olympus Corporation, Japan) was introduced into the pleural cavity through the trocar under direct vision. (i) Non-ablation: The main purpose was to systematically explore the pleural cavity and/or obtain tissue specimen for biopsy. When the thoracoscope reached the cavity, the fluid was aspirated completely but not too hastily. If adhesions were present, mechanical separation was performed by biopsy forceps or cryoprobe, if necessary, by APC or electrocautery (Figure 1). (ii) Thermal ablation: Argon plasma coagulation (APC) technique for pleural tumors was performed after removing the fluid and adhesions. The probe was delivered to the target area through the working channel, with the tip pushed over $1 \mathrm{~cm}$ beyond the distal end of the thoracoscope and within $0.5 \mathrm{~cm}$ of pleural tumors before the ablation. All target therapeutic lesions were located in the parietal pleura. An argon flow of 1-1.5 $\mathrm{L} / \mathrm{min}$ and energy setting of 40-50 J were initially set, and subsequently adjusted according to the extent and depth of the lesions. Argon plasma was applied in bursts of $1-3 \mathrm{~s}$ to achieve suitable results (Figure 2). Postoperative treatment: At the end of the procedure, the pleural cavity was checked to ensure hemostasis. A wide-bore chest tube (intercostal drainage, $24 \mathrm{~F}$ guidewire) was inserted to drain the residual air and fluid, and removed when there was no air leakage and fluid flow $(<100-150 \mathrm{~mL}$ in a $24 \mathrm{~h}$ period).

\section{Catheter Pleural Drainage (CPD)}

A small-bore chest tube (percutaneous drainage, $10 \mathrm{~F}$ guidewire) was placed under ultrasound-guidance. The fluid was drained slowly by a vacuum collector every day (maximum $1.5 \mathrm{~L}$, on a single occasion). In case of aggravation of symptoms (such as cough or chest tightness), the drainage was terminated immediately.

\section{Assessment}

Computed tomography (CT) scan was performed to monitor pleural effusion 6 weeks after the initial treatment and repeated every 6-8 weeks thereafter. In addition, in case of recurrence of dyspnea, CT scan was performed as soon as possible. The formula $\mathrm{D}^{2} \times \mathrm{L}$ was used on soft tissue windows setting of CT image to obtain a rough estimate of the pleural fluid volume (where D was the greatest depth of the effusion in the axial plane, and $\mathrm{L}$ was the greatest length of the effusion in the sagittal plane). This 


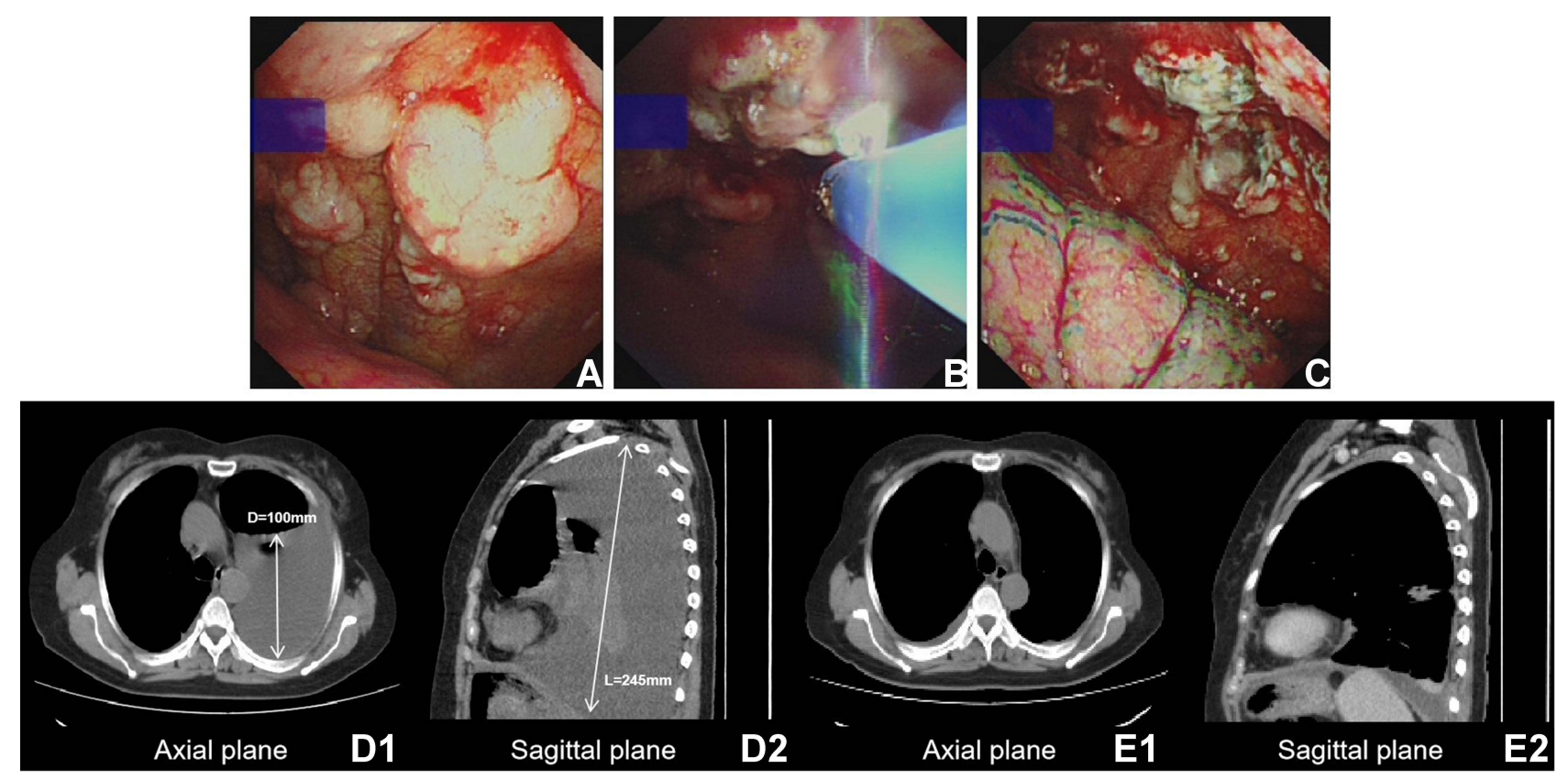

Figure 2 (A-C) Medical thoracoscopy images of a non-small cell lung cancer patient via APC treatment. (A) shows multiple masses studded in the parietal pleura before APC treatment. (B) shows an arc of ionized argon gas formed during APC treatment. (C) shows that the masses have shrank obviously after APC treatment; (D and E) CT imaging of this patient. (DI and D2) show massive MPE in the left side before APC. The calculated volume was about $10^{2} \times 24.5 \mathrm{~cm}=2450 \mathrm{~mL}$. (EI and E2) show resolution of MPE disappeared on the left side and expansion of left lung six weeks after APC.

estimation method has been reported previously. ${ }^{18}$ The response criteria were defined as follows: Complete Response (CR), no pleural effusion and complete resolution of symptoms for $>6$ weeks; Partial Response (PR), more than $50 \%$ reduction in pleural effusion with relief of symptoms lasting for $>6$ weeks; No Response (NR), pleural effusion larger than that defined by PR, or drainage was required within 6 weeks; and Objective Response rate (ORR), defined as $\mathrm{CR}+\mathrm{PR}$. Time to progression (TTP) was defined as the time from initial treatment to the first MPE recurrence confirmed by CT imaging that required further ipsilateral pleural intervention. Overall Survival (OS) was defined as the time from initial treatment (CPD or medical thoracoscopy) to death from any cause.

\section{Statistical Analysis}

Data were expressed as mean \pm standard deviation (SD) or percentages (\%). The baseline characteristics of patients, such as sex, primary tumor, tumor stage, and amount of MPE and the frequency of adverse events, were compared using Pearson's Chi-squared test. Between-group differences with respect to chest-tube duration, patients characteristics (age and KPS score), and vital signs were assessed using an independent $t$-test. CR, PR, and NR rates were analyzed using Mann-Whitney $U$-test. The change in oxygen saturation with change in body position was compared using paired $t$-test. OS and TTP were calculated by Kaplan-Meier estimation and between-group differences assessed using the Log rank test. Cox regression model was used to estimate hazard ratios (HR) with $95 \%$ confidence intervals (CIs). All statistical analyses were performed using SPSS 26.0 and GraphPad Prism 5.0 software. $P$ values $<0.05$ were considered indicative of statistical significance.

\section{Results}

\section{Patients}

The study flowchart is presented in Figure 3. A total of 176 patients were enrolled and divided into three groups: CPD group $(\mathrm{n}=77)$, non-ablation group $(\mathrm{n}=46)$, and thermal ablation group $(n=53)$. After PSM, the sample size for matched pair comparisons were as follows: (i) CPD and thermal ablation $(\mathrm{n}=51)$; (ii) non-ablation and thermal ablation ( $\mathrm{n}=43)$; (iii) CPD and non-ablation ( $\mathrm{n}=$ 45). There were no significant differences in the baseline variables between these groups (Table 1). 


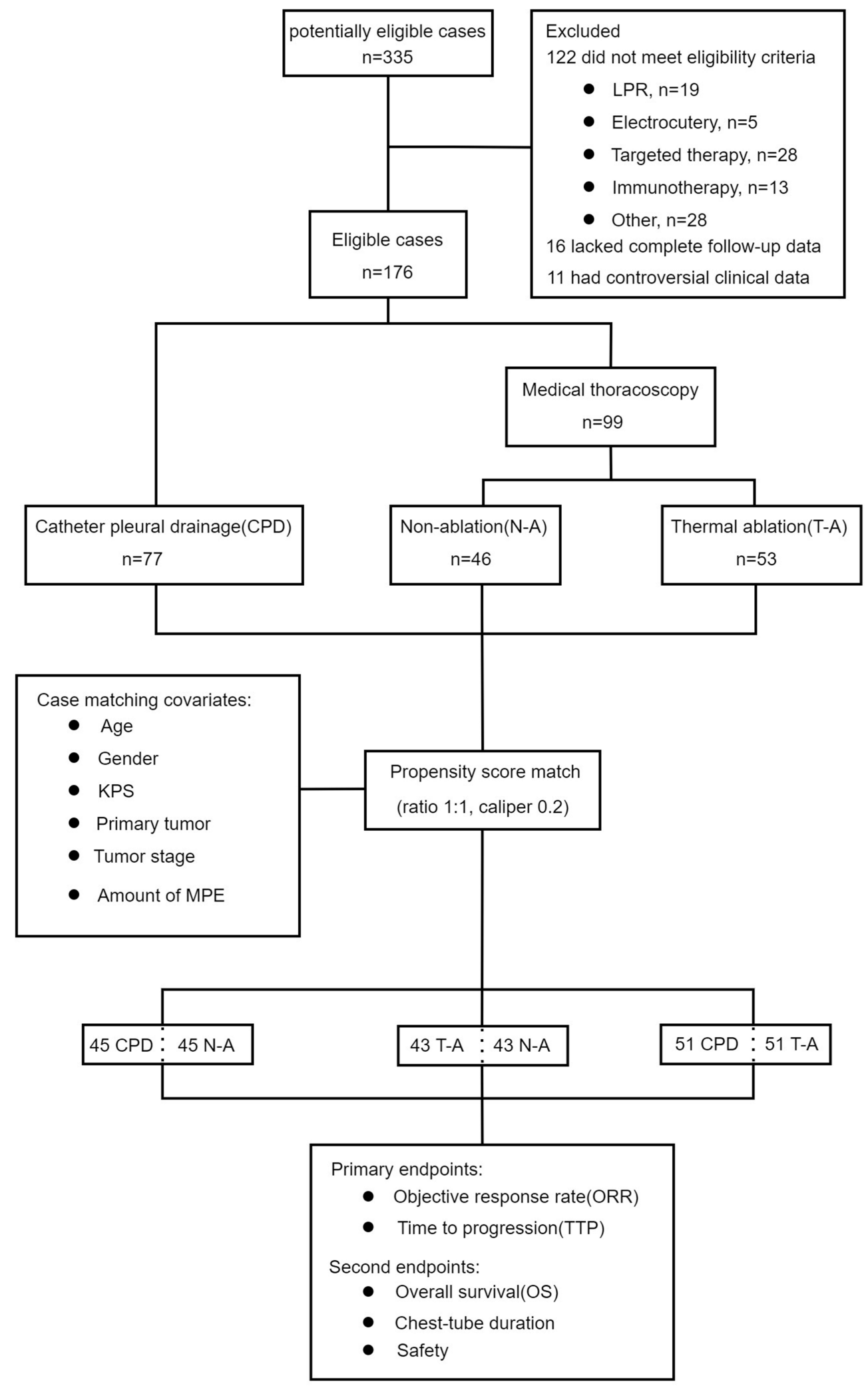

Figure 3 Study flowchart. 


\begin{tabular}{|c|c|c|c|c|c|c|c|}
\hline \multirow{3}{*}{ 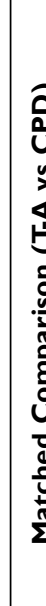 } & 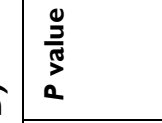 & 员 & $\begin{array}{l}\text { ఫे } \\
\text { t. }\end{array}$ & $\frac{n}{n}$ & 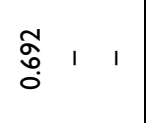 & $\begin{array}{lll}\stackrel{0}{o} & 1 & 1 \\
0 & & \end{array}$ & ôें 11 \\
\hline & 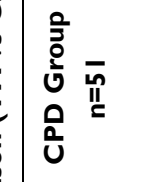 & $\overline{\bar{S}}$ & 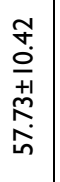 & $\begin{array}{l}\stackrel{n}{\infty} \\
\infty \\
+1 \\
\stackrel{1}{0} \\
\stackrel{N}{N}\end{array}$ & 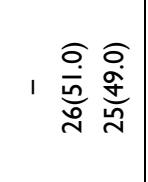 & 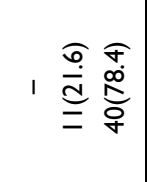 & 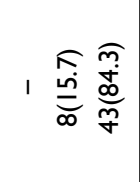 \\
\hline & 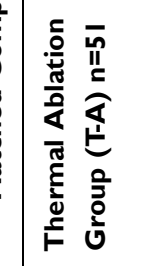 & $\underset{\sim}{\stackrel{\Delta}{N}}$ & 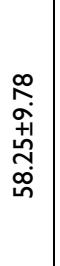 & 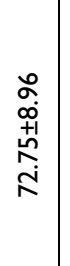 & 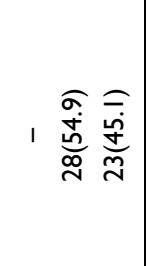 & 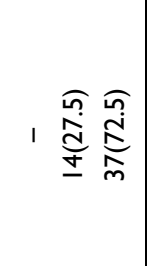 & 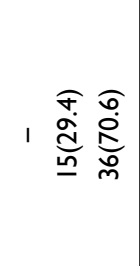 \\
\hline \multirow{3}{*}{$\begin{array}{l}\mathbb{4} \\
\stackrel{1}{2} \\
\vdots\end{array}$} & $\begin{array}{l}\frac{0}{2} \\
\frac{2}{2} \\
a\end{array}$ & $\underset{-}{8}$ & 菅 & $\begin{array}{l}\infty \\
\stackrel{\infty}{\infty} \\
0 \\
0\end{array}$ & 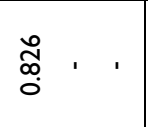 & $\begin{array}{lll}\overline{0} & 1 & 1 \\
0 & & \end{array}$ & $\begin{array}{lll}\stackrel{0}{0} & 1 \\
0 & 1 & 1\end{array}$ \\
\hline & 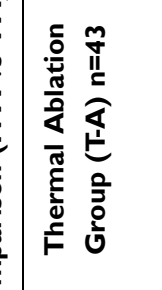 & $\stackrel{\infty}{\stackrel{\infty}{N}}$ & 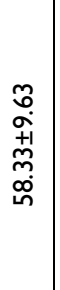 & 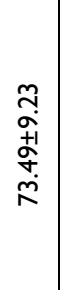 & 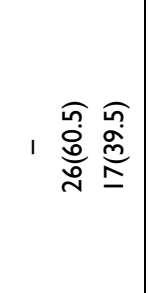 & 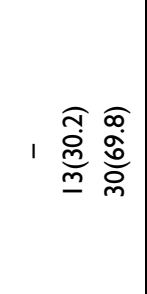 & 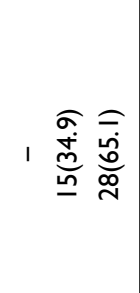 \\
\hline & 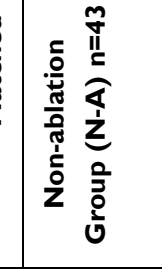 & $\stackrel{\infty}{\stackrel{\infty}{\sim}}$ & 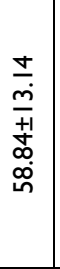 & 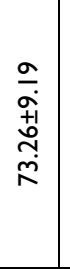 & 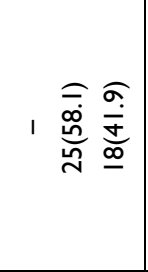 & । & 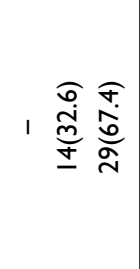 \\
\hline \multirow{3}{*}{ 20 } & $\frac{2}{\frac{2}{N}}$ & $\begin{array}{c}\substack{0 \\
\infty \\
0} \\
0\end{array}$ & $\begin{array}{l}\stackrel{ \pm}{\Delta} \\
0 \\
0\end{array}$ & 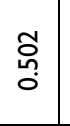 & \begin{tabular}{lll}
\multirow{0}{0}{} & 1 & 1 \\
0 & 1 & 1
\end{tabular} & 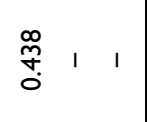 & $\begin{array}{lll}\substack{0 \\
0 \\
0} & 1 & 1\end{array}$ \\
\hline & 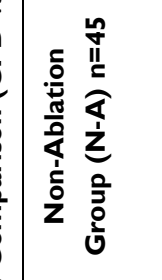 & 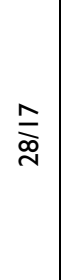 & 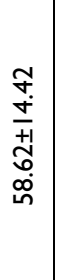 & 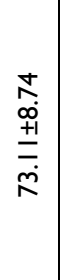 & 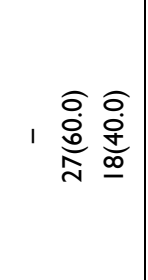 & 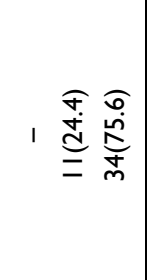 & 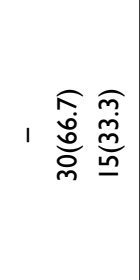 \\
\hline & $\mid \begin{array}{lll}0 & 0 \\
0 & 0 & 0 \\
0\end{array}$ & $\frac{0}{9}$ & $\begin{array}{c}\infty \\
\infty \\
o \\
+1 \\
0 \\
o \\
\infty \\
\infty\end{array}$ & 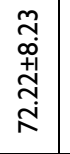 & 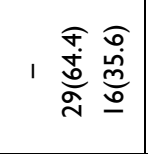 & 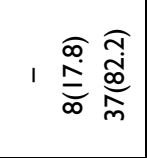 & 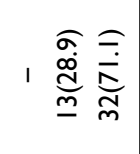 \\
\hline & & 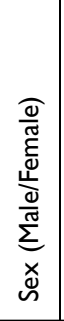 & 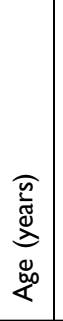 & 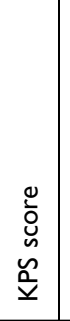 & 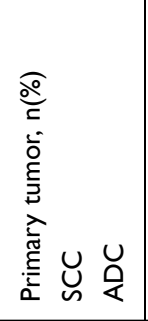 & 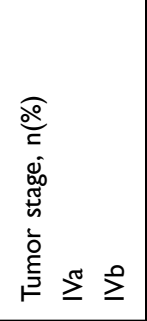 & 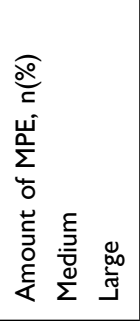 \\
\hline
\end{tabular}



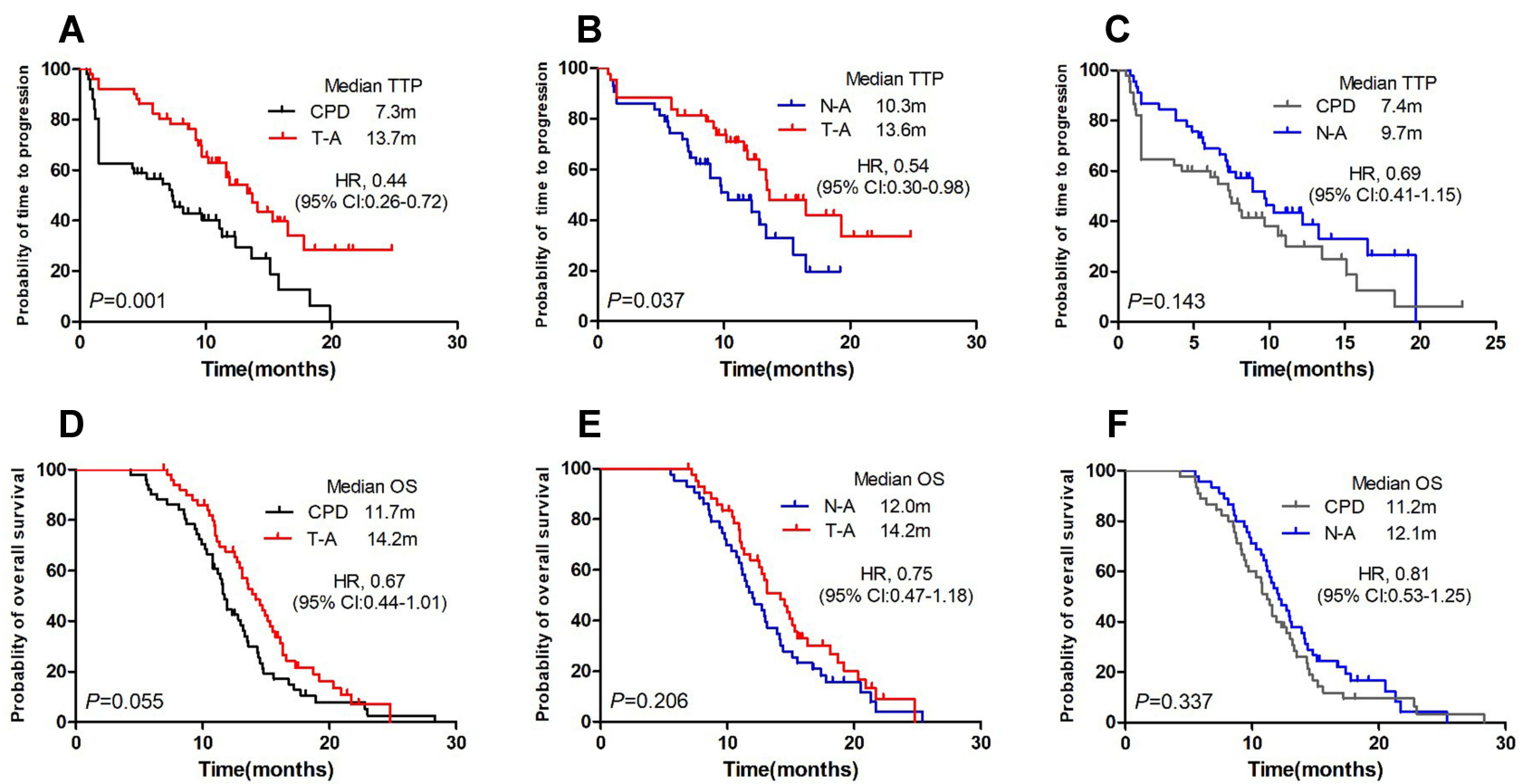

Figure 4 Kaplan-Meier curve of time to progression (A-C) and overall survival (D-F). (A and $\mathbf{D})$ show CPD versus T-A treatment comparison. (B and $\mathbf{E})$ show $\mathrm{N}-\mathrm{A}$ versus T-A treatment comparison. (C and $\mathbf{F}$ ) show CPD versus N-A treatment comparison.

Abbreviations: TTP, time to progression; OS, overall survival; CPD, catheter pleural drainage; N-A, non-ablation; T-A, thermal ablation.

Thermal Ablation Group and CPD Group The thermal ablation group showed significantly longer TTP (median, 13.7 vs 7.3 months; $P=0.001$; Figure $4 \mathrm{~A}$ ), higher ORR $[88.2 \%$ (28 cases achieved $C R$ and 17 cases achieved PR) vs $66.7 \%$ (16 cases achieved $C R$ and 18 cases achieved PR); $P=0.004$; Figure 5A], and shorter chest-tube duration (4.90 vs 7.24 days; $P<0.001$; Figure $6 \mathrm{~A}$ ) compared to the CPD group. OS in the thermal ablation group was numerically better with a marginally significant difference (14.2 vs 11.7 months; $P=0.055$; Figure 4D).

\section{Thermal Ablation Group and Non-Ablation Group}

Thermal ablation group was associated with improved TTP versus non-ablation group (13.6 vs 10.3 months;
$P=0.037$; Figure 4B). However, none of the other endpoints showed any significant between-group difference: ORR ( $88.4 \%$ vs $86.0 \% ; P=0.319$; Figure $5 \mathrm{~B}$ ), chest-tube duration ( 4.79 vs 5.81 days; $P=0.059$; Figure $6 \mathrm{~B}$ ), and $\mathrm{OS}$ (14.2 vs 12.0 months; $P=0.206$; Figure $4 \mathrm{E}$ ).

\section{Non-Ablation Group and CPD Group}

ORR was significantly higher in non-ablation group (84.4\%; 18 cases achieved CR and 20 cases achieved PR) compared with CPD group (64.4\%; 12 cases achieved $\mathrm{CR}$ and 17 cases achieved PR) ( $P=0.042 ;$ Figure $5 C)$. The median chest-tube duration was 5.73 days in the non-ablation group and 7.33 days in the CPD group ( $P=0.010$; Figure $6 \mathrm{C}$ ). There were no significant differences between the non-ablation group and the CPD group with respect to TTP or OS (Figure 4C and F).
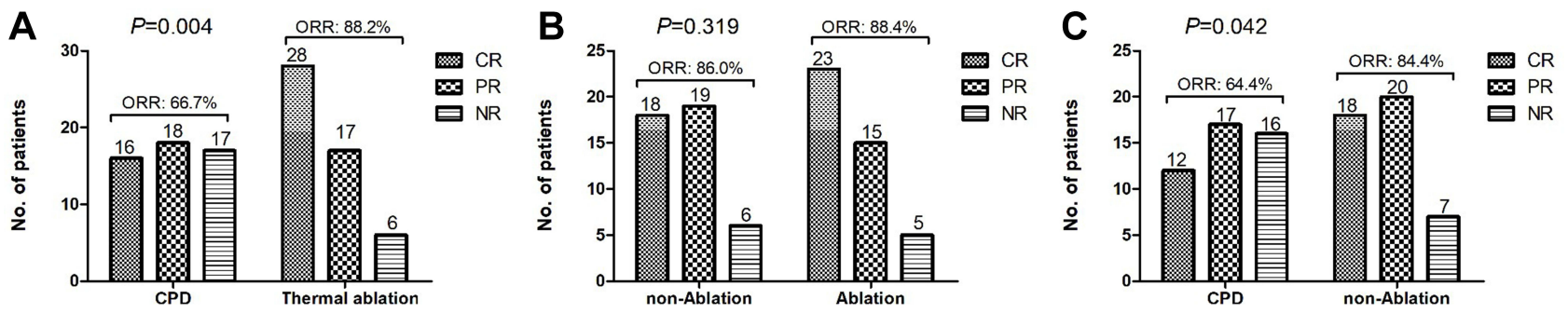

Figure 5 Comparison of objective response rate (ORR) between matched groups. (A) CPD versus thermal ablation treatment comparison. (B) Non-ablation versus ablation treatment comparison. (C) CPD versus non-ablation treatment comparison.

Abbreviations: CPD, catheter pleural drainage; CR, complete response; PR, partial response; NR, no response. 

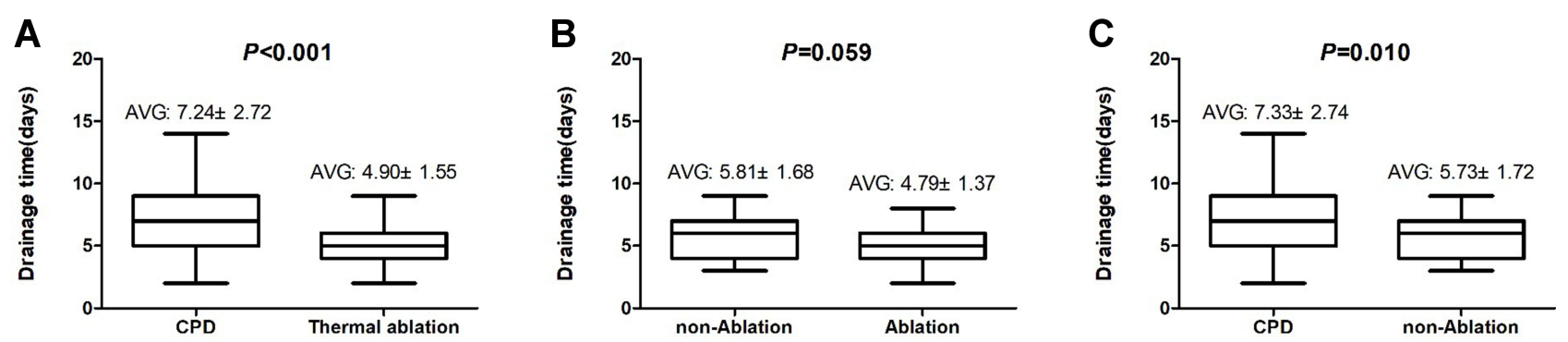

Figure 6 Chest-tube duration of three matched pairs. (A) CPD versus thermal ablation treatment comparison. (B) Non-ablation versus ablation treatment comparison. (C) CPD versus non-ablation treatment comparison.

Abbreviations: CPD, catheter pleural drainage; AVG, average value.

\section{Complications and Vital Signs}

The most common adverse events were postoperative chest pain [9 (20.9\%) of 43 patients in the non-ablation group, 11 (25.6\%) of 43 patients in the thermal ablation group], intraoperative bleeding [2 (4.7\%) and 3(7.0\%)], and fever [3(7.0\%) and $4(9.3 \%)$ ] (Table 2). None of the patients experienced any serious adverse events, such as re-expansion pulmonary edema. There were no significant differences between the thermal ablation group and the non-ablation group with respect to vital signs, such as heart rate, respiratory rate, mean arterial pressure, or oxygen saturation. Moreover, in all 99 patients who underwent medical thoracoscopy, we observed a phenomenon of significant change in oxygen saturation change in different body positions [spine position $(96.8 \pm 1.5) \%$, lateral decubitus position $(98.2 \pm 1.1) \%$; $P<0.001]$.

\section{Discussion}

The main aim of management of MPE is to achieve immediate symptom improvement and avoid recurrence. Although indwelling pleural catheter and pleurodesis are currently considered as the preferred first-line choices, these modalities have no direct mechanical debulking effect on tumors in the pleura. We attempted to explore a minimally invasive method that allows more effective fluid drainage, as well as reduction of metastatic tumors. Medical thoracoscopy, which is considerably less invasive, less expensive, and associated with fewer complications compared with surgery procedures, is expected to play an important role in intrapleural therapy.

In the medical thoracoscopic non-ablation group, pleural fluid was completely aspirated, and adhesions were removed to clear any encapsulated fluid as much as possible. The ORR and chest-tube duration in this group were both better than those in the CPD group. We inferred that medical thoracoscopy offered two advantages over CPD: (1) Removal of adhesions: $60 \%$ of patients with MPE were found to have adhesions in the pleural cavity, leading to pleural thickening, encapsulated effusion, and collapsed lung. ${ }^{19}$ Medical thoracoscopy was used to visualize and remove the adhesions directly to reverse lung atelectasis and improve drainage efficiency. (2) Fluid removal: AMPLE-2 trial suggested that daily indwelling pleural catheter drainage was more effective in promoting spontaneous pleurodesis and thus might improve the quality of life. ${ }^{20}$ However,

Table 2 Complications and Vital Signs in the Matched Cohort Between the Thermal Ablation Group and the Non-Ablation Group

\begin{tabular}{|c|c|c|c|c|}
\hline \multicolumn{2}{|l|}{ Groups } & \multirow{2}{*}{$\begin{array}{c}\text { Thermal Ablation }(n=43) \\
1 \mathrm{I}(25.6)\end{array}$} & \multirow{2}{*}{$\frac{\text { Non-Ablation }(n=43)}{9(20.9)}$} & \multirow{2}{*}{$\begin{array}{c}\boldsymbol{P} \text { value } \\
0.978\end{array}$} \\
\hline Complications & Chest pain, $n(\%)$ & & & \\
\hline & Fever, $\mathrm{n}(\%)$ & $3(7.0)$ & $2(4.7)$ & \\
\hline & Intraoperative bleeding, $\mathrm{n}(\%)$ & $4(9.3)$ & $3(7.0)$ & \\
\hline \multirow[t]{4}{*}{ Vital signs } & Heart rate (beats/min) & $90.9 \pm 15.8$ & $88.8 \pm 12.3$ & 0.489 \\
\hline & Respiratory rate (breaths/min) & $19.4 \pm 2.8$ & $19.1 \pm 2.0$ & 0.691 \\
\hline & Oxygen saturation (\%) & $95.7 \pm 2.4$ & $96.2 \pm 2.5$ & 0.321 \\
\hline & Mean arterial pressure $(\mathrm{mmHg})$ & $91.7 \pm 2.2$ & $91.2 \pm 3.0$ & 0.440 \\
\hline
\end{tabular}

Notes: Chest pain was defined as pain numeric rating scale(NRS) score $\geq 3$; heart rate, respiratory rate and mean arterial pressure took the maximum value, oxygen saturation took the minimum value during the operation. 
single drainage of a large amount of fluid may cause mediastinal shift or re-expansion pulmonary edema due to the change in intrathoracic pressure. ${ }^{21}$ As the effusion is produced constantly, prolonged drainage duration would result in excessive protein loss. On the contrary, use of medical thoracoscopy, which allows fluid aspiration under direct vision, allows the air to enter the pleural cavity through the cannula and to replace the aspirated fluid. This helps maintain the intrapleural pressure. Due to this, it is safe to aspirate the pleural fluid completely on a single occasion under direct vision. None of the 99 patients who underwent medical thoracoscopy in our study developed immediate re-expansion edema. In addition, pleural effusion contains cancer cells, lymphoid and myeloid immune cells, which in turn may promote the pleura to produce effusion. Therefore, application of medical thoracoscopy may help improve the efficacy of MPE management due to the removal of adhesions and fluid. Nevertheless, in this study, we found no TTP or OS advantages of medical thoracoscopy non-ablation group compared to CPD group. This may imply that the benefits of medical thoracoscopy non-ablation therapy may only be short term and are not sustained.

In the medical thoracoscopy thermal ablation group, the TTP reached statistical significance compared with not only the CPD group but also the non-ablation group. Although there was no significant difference in the ORR between the thermal ablation group and the non-ablation group, the higher CR rate in the thermal ablation group was notable OS tended to be longer in the thermal ablation group versus CPD group with a marginally significant difference. These results suggested that thermal ablation may have long-term efficacy. We believe that the superiority of thermal ablation therapy over nonablation for the metastatic tumors in the parietal pleura is attributable to the following factors: (1) It achieves instant coagulation necrosis of tumor tissues, reducing the tumor burden in the parietal pleura and the MPE. (2) It causes mechanical irritation and aseptic inflammation in the pleura, achieving a similar effect as chemical pleurodesis. (3) It may activate a possible systemic or localized antitumor immune response, inducing the death or destruction of tumor cells. ${ }^{22,23}$ (4) It may have synergistic effects in combination with chemotherapy. $^{24}$

Thermal ablation mainly includes APC, LPR and electrocautery. However, in this study, only APC was employed as the thermal ablation method. APC does not require direct contact with the target tissues. An arc of ionized argon gas is formed via a flexible probe, which can be moved back and forth, easily expanding the area of heat destruction and desiccation, with a penetration depth of just a few millimeters. Similarly, LPR was commonly used to cut or destroy superficial tumors with highintensity energy directed straightly towards the target. Nevertheless, the area of ablation by APC was much larger than that by LPR. Furthermore, APC was aimed around the target located at the lateral side of the probe, making it very suitable for inaccessible tumors. Thus, APC may be more suitable for the treatment of superficial and spreading tumors just like pleural disseminated tumors. In terms of complications, the LPR technique is more prone to cause chest pain, which may be due to deeper penetration of tissues by LPR. In addition, LPR is more likely to cause bleeding; therefore, the risk of implantation metastasis in the pleural cavity should be carefully considered. On the contrary, APC offers the benefit of less intraoperative bleeding, which can effectively prevent implantation metastasis. Moreover, its lower penetration depth reduces the risk of severe chest pain. As for electrocautery, it has several obvious demerits, such as low efficiency resulting in longer operation time. Moreover, electrocautery relies on direct tissue contact; therefore, it is difficult to manage the depth, and the probe may easily stick to the carbonized tissue. Of the 5 patients who underwent this technique, 3 patients developed chest pain. For these reasons, we excluded LPR and electrocautery from this study.

The current guidelines recommend the use of talc pleurodesis for the management of MPE. These recommendations are based on TIME2 and AMPLE clinical trials in which the one-year survival rates were $13.0 \%$ and $28.2 \%$, respectively. ${ }^{25,26}$ In our cohort, the one-year survival rate after thermal ablation therapy was $66.0 \%$ (Table 3). We could not directly compare these results because the effect of some factors, such as differences in systemic antitumor therapy and baseline characteristics of patients could not be ruled out. However, according to a systemic review by Migliore et $\mathrm{al}^{13} 13$ out of $21(62.0 \%)$ patients with non-small cell lung cancer who underwent cytoreductive surgery and hyperthermic intrathoracic chemotherapy were alive at 1 year (Table 4). ${ }^{27-30}$ This survival rate and the baseline characteristics of these 21 patients were similar to those of our cohort. The possible reason for the similar result was the reduction of pleural tumors, an effect not shared by talc pleurodesis.

We also observed an interesting phenomenon wherein patients showed slight improvement in dyspnea upon changing the body position from supine position to lateral decubitus position with healthy side down, with concomitant 
Table 3 Comparison of Outcomes of Thermal Ablation in the Present Study with Those of Talc Pleurodesis in Previous Studies

\begin{tabular}{|c|c|c|c|c|c|c|}
\hline $\begin{array}{l}\text { Studies } \\
\text { [Ref.] }\end{array}$ & Time of Enrollment & Country/Region & $\begin{array}{l}\text { Journal/ } \\
\text { Year }\end{array}$ & Cases & Methods & $\begin{array}{c}\text { I-Year Survival } \\
\text { Rate }\end{array}$ \\
\hline Davies et $\mathrm{al}^{25}$ & $\begin{array}{c}\text { April 2007-February } \\
2011\end{array}$ & UK & JAMA/2012 & 54 & $\begin{array}{c}\text { Talc } \\
\text { pleurodesis }\end{array}$ & $13.0 \%(7 / 54)$ \\
\hline Thomas et $\mathrm{al}^{26}$ & July 2012 -October 2014 & $\begin{array}{c}\text { Australia New-Zealand } \\
\text { Singapore } \\
\text { Hong Kong }\end{array}$ & JAMA/2017 & 71 & $\begin{array}{c}\text { Talc } \\
\text { pleurodesis }\end{array}$ & $28.2 \%(20 / 7 \mathrm{I})$ \\
\hline Our Study & May 2015-June 2019 & China & - & 53 & $\begin{array}{l}\text { Thermal } \\
\text { ablation }\end{array}$ & $66.0 \%(35 / 53)$ \\
\hline
\end{tabular}

Table 4 Experiences with Cytoreductive Surgery and Hyperthermic Intrathoracic Chemotherapy in the Studies Included in the Systematic Review by Migliore et al

\begin{tabular}{|l|c|c|c|c|}
\hline $\begin{array}{l}\text { First Author } \\
\text { [Ref.] }\end{array}$ & Year & Country & $\begin{array}{c}\text { Patients, } \\
\text { n }\end{array}$ & $\begin{array}{c}\text { I-Year } \\
\text { Survival Rate }\end{array}$ \\
\hline Monneuse $^{27}$ & 2003 & France & 3 & $62 \%(13 / 21)$ \\
Shigemura $^{28}$ & 2003 & Japan & 5 & \\
Isık $^{29}$ & 2013 & Turkey & II & \\
Migliore $^{30}$ & 2015 & Italy & 2 & \\
\hline
\end{tabular}

Note: Citation: European Respiratory Review 2019 28: 190018; DOI: 10.1183/16000617.0018-2019.

increase in oxygen saturation. In this study, we analyzed the change in $\mathrm{SPO}_{2} \%$ with positional changes in 99 patients who underwent medical thoracoscopy. We found that there was a significant difference. This may be due to the redistribution of blood flow from the affected lung to the contralateral lung with better ventilation, improving the oxygenation. ${ }^{31}$ This implies that the procedure of medical thoracoscopy may become safer through the change in body position. Further, the incidence of adverse events did not increase when we performed thermal therapy under medical thoracoscopy.

\section{Limitations}

Although the results are encouraging, some limitations of our study should be considered. (1) This was a single-center retrospective study with a small sample size. The effect of selection bias on our results cannot be ruled out despite efforts to minimize it. For example, two investigators screened the data independently, strict inclusion and exclusion criteria were followed, and PSM was conducted. Thus, prospective multi-center randomized controlled trials are required to provide more robust evidence. (2) We did not use the imaging techniques to directly evaluate the efficacy of pleural tumors, such as size and number, due to limitations of ultrasound or CT imaging in the diagnosis of pleural lesions, and the high cost of PET-CT, which has high sensitivity and specificity. (3) Although thermal ablation is useful for reducing pleural tumors, we did not use it on the nodules of visceral pleura, and it is not quite adequate for diffuse lesions or lesions that are located at sites that are not accessible with thoracoscopy. We intend to combine with photodynamic therapy (PDT) to address this shortcoming in future prospective study.

\section{Conclusions}

Medical thoracoscopy is a minimally invasive procedure, which is even safer when patients are placed in a lateral decubitus position with a healthy side down to improve oxygenation. It is safe to aspirate the pleural fluid completely while removing the pleural adhesions under direct vision as much as possible to promote lung expansion and lung function. Therefore, the short-term efficacy (ORR and chest-tube duration) for the management of MPE by medical thoracoscopy is better than that by CPD. Medical thoracoscopic thermal ablation (APC technique) therapy can improve not only the short-term efficacy of MPE but also the time to progression. Although this is a retrospective study, the medical thoracoscopic APC technique seems to be a promising potential treatment option for the management of metastatic pleural tumors with malignant effusion.

\section{Acknowledgments}

The authors would like to thank the staff of Endoscopy Center of Integrated Hospital of Traditional Chinese Medicine, Southern Medical University for assistance with medical thoracoscopy procedures. Zhonglun Mai and Bin Feng are co-first authors for this study. Qixiao 
Feng and Zhonglun Mai contributed equally as co-corresponding authors for this study.

\section{Disclosure}

The authors report no conflicts of interest in this work.

\section{References}

1. Clive AO, Jones HE, Bhatnagar R, Preston NJ, Maskell N. Interventions for the management of malignant pleural effusions: a network meta-analysis. Cochrane Database Syst Rev. 2016;(5): CD010529. doi:10.1002/14651858.CD010529.pub2

2. Lepus CM, Vivero M. Updates in effusion cytology. Surg Pathol Clin. 2018;11(3):523-544. doi:10.1016/j.path.2018.05.003

3. Feller-Kopman D, Light R. Pleural disease. N Engl J Med. 2018;378 (18):1754. doi:10.1056/NEJMra1403503

4. Froudarakis ME. Pleural effusion in lung cancer: more questions than answers. Respiration. 2012;83(5):367-376. doi:10.1159/000338169

5. Psallidas I, Kalomenidis I, Porcel JM, Robinson BW, Stathopoulos GT. Malignant pleural effusion: from bench to bedside. Eur Respir Rev. 2016;25(140):189-198. doi:10.1183/16000617.0019-2016

6. Mummadi S, Kumbam A, Hahn PY. Malignant pleural effusions and the role of talc poudrage and talc slurry: a systematic review and meta-analysis. F1000Res. 2014;3:254. doi:10.12688/f1000res earch.5538.1

7. Bibby AC, Dorn P, Psallidas I, et al. ERS/EACTS statement on the management of malignant pleural effusions. Eur Respir J. 2018;52 (1):1800349. doi:10.1183/13993003.00349-2018

8. Feller-Kopman DJ, Reddy CB, DeCamp MM, et al. Management of malignant pleural effusions. an official ATS/STS/STR clinical practice guideline. Am J Respir Crit Care Med. 2018;198(7):839-849.

9. Wahla AS, Uzbeck M, El Sameed YA, Zoumot Z. Managing malignant pleural effusion. Cleve Clin J Med. 2019;86(2):95-99. doi:10.3949/ccjm.86a.17095

10. MacEachern P, Tremblay A. Pleural controversy: pleurodesis versus indwelling pleural catheters for malignant effusions. Respirology. 2011;16(5):747-754. doi:10.1111/j.1440-1843.2011.01986.x

11. Evans TJ, Sivakumar P, Ahmed L. Progressive respiratory failure: a rare complication after graded talc pleurodesis. Br J Hosp Med. 2017;78(5):294-295. doi:10.12968/hmed.2017.78.5.294

12. Keeratichananont W, Kaewdech A, Keeratichananont S. Efficacy and safety profile of autologous blood versus talc pleurodesis for malignant pleural effusion: a randomized controlled trial. Ther Adv Respir Dis. 2018;12:1753466618816625. doi:10.1177/1753466618816625

13. Migliore M, Nardini M. Does cytoreduction surgery and hyperthermic intrathoracic chemotherapy prolong survival in patients with N0-N1 nonsmall cell lung cancer and malignant pleural effusion? Eur Respir Rev. 2019;28(153). doi:10.1183/16000617.0018-2019

14. Wan YY, Zhai CC, Lin XS, et al. Safety and complications of medical thoracoscopy in the management of pleural diseases. $B M C$ Pulm Med. 2019;19(1):125. doi:10.1186/s12890-019-0888-5

15. Roberts ME, Neville E, Berrisford RG, Antunes G, Ali NJ. Management of a malignant pleural effusion: British thoracic society pleural disease guideline 2010. Thorax. 2010;65(Suppl 2):ii32-40. doi:10.1136/thx.2010.136994

16. Shepherd RW, Radchenko C. Bronchoscopic ablation techniques in the management of lung cancer. Ann Transl Med. 2019;7(15):362. doi:10.21037/atm.2019.04.47
17. Jin F, Li Q, Li S, et al. Interventional bronchoscopy for the treatment of malignant central airway stenosis: an expert recommendation for China. Respiration. 2019;97(5):484-494. doi:10.1159/000497213

18. Porcel JM, Pardina M, Aleman C, Pallisa E, Light RW, Bielsa S. Computed tomography scoring system for discriminating between parapneumonic effusions eventually drained and those cured only with antibiotics. Respirology. 2017;22(6):1199-1204. doi:10.1111/ resp. 13040

19. Bielsa S, Martin-Juan J, Porcel JM, Rodriguez-Panadero F. Diagnostic and prognostic implications of pleural adhesions in malignant effusions. $J$ Thorac Oncol. 2008;3(11):1251-1256. doi:10.1097/ JTO.0b013e318189f53d

20. Muruganandan S, Azzopardi M, Fitzgerald DB, et al. Aggressive versus symptom-guided drainage of malignant pleural effusion via indwelling pleural catheters (AMPLE-2): an open-label randomised trial. Lancet Respir Med. 2018;6(9):671-680. doi:10.1016/S22132600(18)30288-1

21. Kesieme EB, Dongo A, Ezemba N, Irekpita E, Jebbin N, Kesieme C. Tube thoracostomy: complications and its management. Pulm Med. 2012;2012:256878. doi:10.1155/2012/256878

22. Bibby AC, Clive AO, Slade GC, et al. Survival in patients with malignant pleural effusions who developed pleural infection: a retrospective case review from six UK centers. Chest. 2015;148 (1):235-241. doi:10.1378/chest.14-2199

23. Donnenberg AD, Luketich JD, Dhupar R, Donnenberg VS. Treatment of malignant pleural effusions: the case for localized immunotherapy. J Immunother Cancer. 2019;7(1):110. doi:10.11 86/s40425-019-0590-4

24. Chu KF, Dupuy DE. Thermal ablation of tumours: biological mechanisms and advances in therapy. Nat Rev Cancer. 2014;14 (3):199-208. doi:10.1038/nrc3672

25. Davies HE, Mishra EK, Kahan BC, et al. Effect of an indwelling pleural catheter vs chest tube and talc pleurodesis for relieving dyspnea in patients with malignant pleural effusion: the TIME2 randomized controlled trial. JAMA. 2012;307(22):2383-2389. doi:10.1001/jama.2012.5535

26. Thomas R, Fysh ETH, Smith NA, et al. Effect of an indwelling pleural catheter vs Talc pleurodesis on hospitalization days in patients with malignant pleural effusion: the AMPLE randomized clinical trial. JAMA. 2017;318(19):1903-1912. doi:10.1001/jama.2017.17426

27. Monneuse O, Beaujard AC, Guibert B, et al. Long-term results of intrathoracic chemohyperthermia (ITCH) for the treatment of pleural malignancies. Br J Cancer. 2003;88(12):1839-1843. doi:10.1038/sj. bjc. 6601000

28. Shigemura N, Akashi A, Ohta M, Matsuda H. Combined surgery of intrapleural perfusion hyperthermic chemotherapy and panpleuropneumonectomy for lung cancer with advanced pleural spread: a pilot study. Interact Cardiovasc Thorac Surg. 2003;2(4):671-675. doi:10.1016/S1569-9293(03)00197-X

29. Isik AF, Sanli M, Yilmaz M, et al. Intrapleural hyperthermic perfusion chemotherapy in subjects with metastatic pleural malignancies. Respir Med. 2013;107(5):762-767. doi:10.1016/j.rmed.2013.01.010

30. Migliore M, Calvo D, Criscione A, et al. Cytoreductive surgery and hyperthermic intrapleural chemotherapy for malignant pleural diseases: preliminary experience. Future Oncol. 2015;11(2 Suppl):47-52. doi:10.2217/fon.14.256

31. Neagley SR, Zwillich CW. The effect of positional changes on oxygenation in patients with pleural effusions. Chest. 1985;88 (5):714-717. doi:10.1378/chest.88.5.714 


\section{Publish your work in this journal}

The International Journal of General Medicine is an international, peer-reviewed open-access journal that focuses on general and internal medicine, pathogenesis, epidemiology, diagnosis, monitoring and treatment protocols. The journal is characterized by the rapid reporting of reviews, original research and clinical studies across all disease areas. The manuscript management system is completely online and includes a very quick and fair peer-review system, which is all easy to use. Visit http://www.dovepress.com/ testimonials.php to read real quotes from published authors.

Submit your manuscript here: https://www.dovepress.com/international-journal-of-general-medicine-journal 